\title{
İstanbul Avrupa Yakası Fitness Antrenörlerinin Tükenmişlik, Stresle Başa Çıkma ve Yardım Arama Tutumları ${ }^{1}$
}

DOI: $10.26466 /$ opus.784449

\author{
Seval Kayğusuz* - Elif Karagün** \\ *Öğr. Gör., İstanbul Gedik Üniversitesi \\ E-Posta: sevalkaygusuz@gmail.com \\ ORCID: 0000-0003-0699-8441 \\ ${ }^{* *}$ Doç. Dr., Kocaeli Üniversitesi \\ E-Posta: elif.karagun@gmail.com \\ ORCID: $\underline{0000-0003-1974-4117}$
}

\begin{abstract}
Öz
Bu çalışmanın amacı, İstanbul İli Avrupa Yakası'nda bulunan fitness antrenörlerinin tükenmişlik duygusu, stresle başa çıkma ve yardım arama tutumların belirlemektir. Belirlenen bu özelliklerin de; yaş, cinsiyet, günlük mesai saati, başka bir meslekle uğraşma, düzenli spor yapma ve ortalama haftalik yapılan antrenman saati gibi değişkenlere göre farklılık gösterip göstermediğini incelemektir. Bu amaç doğrultusunda; Avrupa Yakası'nda bulunan 129'u kadın 272'si erkek olmak üzere toplam 401 fitness antrenörüne demografik özelliklerini belirlemek amacı ile araştırmacıların oluşturduğu Kişisel Bilgi Formu, Çapri (2006) tarafindan Türkçe'ye uyarlanan Tükenmişlik Ölçeği, Türküm (2002) tarafınfan Türkçe'ye uyarlanan Stresle Başa Çıkma Ölçeği ilee Özbay, Palancı ve Koç (1999) tarafindan geliştirilen Yardım Arama Tutumları Ölçeği kullanılmıştır. Veriler SPSS 22.00 paket programında analiz edildiğinde; normal dağılıma uymadıkları için Man Whitney U ve Kruskal Wallis testleri kullanılmıştır.Analiz sonuçlarına incelendiğinde tükenmişlik duygu durum puanlar yaşa göre, stresle başa çıkma puanları ise yaş ve düzenli spor yapma durumlarına göre anlamlı bulunmuştur. Yardım arama tutumlart ise cinsiyet ve düzenli spor yapma durumlarına göre anlaml farklllk göstermiştir.
\end{abstract}

Anahtar Kelimeler: stres, yardım arama, tükenmişlik, antrenör, fitness

\footnotetext{
${ }^{1}$ Bu çalışma Doç. Dr. Elif Karagün danışmanlığında Kocaeli Üniversitesi Sağlık Bilimleri Enstitüsünde yürütülen "Istanbul Avrupa Yakası Fitness Antrenörlerinin Tükenmişlik, Stresle Başa Çıkma ve Yardım Arama Tutumları" başı।klı yüksek lisans tezinden üretilmiștir. 16. Uluslararası Spor Bilimleri Kongresinde Sözel Bildiri olarak sunulmuştur.
} 
ISSN: 2528-9527

E-ISSN : 2528-9535

YIl Year: 10

Cilt Volume: 17

Sayı Issue: 35

Mart March 2021

Makalenin Gelis Tarihi Received Date. 24/08/2020 Makalenin Kabul Tarihi Accepted Date. 17/03/2021

\title{
Burnout, Stress Coping and Help-seeking Attitudes of Istanbul European Side Fitness Coaches
}

\begin{abstract}
The aim of this study is to determine the feelings of burnout, coping with stress, and seeking help from fitness trainers in the European Side of Istanbul Province. In this study, it was examined whether it differs according to variables such as age, gender, daily working hours, dealing with another profession, regular sports, and average weekly training hours. Personal Information Form, Burnout Scale, Stress Coping Scale, and Help-Seeking were used as attitude scales in the study, and A total of 401 fitness trainers, 129 women, and 272 men, from the European Side of Istanbul, participated in this study. When the data were analyzed in the SPSS 22.00 package program, Man Whitney U and Krus$\mathrm{kal}$ Wallis tests were used because they did not conform to normal distribution. According to the analysis results; The emotional state of burnout was found to differ significantly by age. The scores for coping with stress differed significantly according to age and regular exercise. Help-seeking attitudes differed significantly according to gender and regular sports.
\end{abstract}

Keywords: stress, help-seeking attitudes, burnout, trainer, fitness 


\section{Giriş}

Günümüzde teknolojik gelişmeler, istihdam sorunları, kentleşme gibi pek çok değişimlerin stres için birer tetikleyici olduğu bilinir. Stres, Dünya Sağlık Örgütü tarafından "Geleneksel uyum sağlama yönteminin; psikolojik, sosyal ve ekonomik koşullarda yetersiz kalması" şeklinde tanımlamıştır (Illbars, 1994, s.178). Olumsuz ilişkiler gibi pek çok faktörün yanı sıra çevre ortamında doyurucu etkinliklerde bulunulmamasının da strese yol açtığ ifade edilmiştir (Kut, 1994, s.181). Strese yol açan bu etmenlerin yanında, stresin uzun süre devam etmesi ile birlikte ortaya çıan tükenme ise; insanlarla sürekli iletişim içerisinde olma sonucunda oluşan ve devam eden bir duygusal gerginlik karşısında ortaya çıkan tepki olarak görülmektedir (Bezliudnyi, Kravchenko, Maksymchuk, Mishchenko ve Maksymchuk, 2019; Maslach, Schaufeli ve Leiter, 2001; Samur ve Samur, 2017; Torelli ve Gmelch, 1992). Tükenmişlik, fiziksel tükenme, umutsuzluk, duygusal yitim gibi pek çok belirtileri içeren; fiziksel, duygusal ve ruhsal bir çöküş içine girme olarak açıklanmıştır (Brown, 2003; Enzmann, Schaufeli, Janssen ve Rozeman, 1998). Inssanlara hizmet sunmaya yönelik olan mesleklerde ortaya çıkan tükenmenin; insan ilişkileri arttıkça, ortaya çıkma olasılı̆̆ının da arttığı belirtilmiştir (Babaoğlan, Altun ve Çakan, 2010). Literatüre bakıldığında; stresle ve uzun yaşanan stres süreci sonucunda ortaya çıkan tükenme ile baş etmek için pek çok yöntemlerin yanında rekreatif içerikli egzersiz programlarının önerildiği de belirlenmiştir (Aylaz, Güllü ve Güneş, 2011, s.174; Byrne ve Byrne 1993; Salmon, 2001). Toplumumuzda insanların stres ve tükenme ile baş etmek için, özellikle rekreasyonel amaçlı düzenlenen birçok egzersiz programlarına katıldıkları, bu egzersiz programları içerisinde ise ağırlıklı olarak fitness merkezlerinin yer aldığı bilinmektedir. İnsanların stres ile baş etmek, yenilenmek, rutinden kurtularak sağlıklı kalabilmek için başvurdukları fitness merkezlerinde iletişime girdikleri ve eğitim aldıkları kişiler ise antrenörlerdir. Antrenör, bir meslek grubu olarak; gerekli stratejik, teknik bilgileri birleştirici bir tür teknisyen olarak değerlendirilmiştir. Antrenörler aynı zamanda organizatör, yönetici, motivasyon sağlayıcı, lider ve sporcusunun yeterliliğini geliştiren bir eğitimci olarak da tanımlanmıştır (Dolaşır, 2006). Antrenörlükle ilgili yapılmış bu tanımlara bakıldığında antrenör sporda bir tür mihenk taşı, bir temel olarak değerlendirilmiştir. Bu meslek grubuna, yani spor eğitiminde önemli rolü olan antrenöre olanak 
sunulması, eğitim desteğinin verilmesi, mesleki beceriler ve yeterliliklerinin geliştirilmesi ile mesleğe sunacağı katkısının da daha iyi olacağı belirtilmiştir (Dolaşır, 2006; Lyle, 2002).

Antrenörler ile ilgili tanımlarda, genelde performans sporuna yönelik açılamaların yer aldığı görülse de, performans sporu dışında; fiziksel, ruhsal ve sosyal sağlığı geliştirmek veya korumak için yapılan ve bir tür serbest zaman etkinlikleri olan egzersiz çalışmalarında da yer aldıkları görülmektedir. Günlük yaşamda özellikle yaşam kalitesi açısından stresle baş etmede egzersiz programları önerilmektedir (Alpaslan, 2012, s.184; Ekeland, Heian, Hagen, Abbott ve Nordheim, 2004). Günümüzde egzersiz programlarının yürütüldüğü kurumlardan biri de fitness merkezleridir. Fitness merkezleri, serbest zaman diliminde; rahatlamak, zinde kalmak, streslerden kurtulmak ve tükenmeye yol açan günlük rutinden uzaklaşmak için insanların başvurduğu merkezler olduğu herkesin bildiği bir durumdur. Bu merkezlere başvuran bireyleri yönlendiren ve beklentilerini karşılayacak programın uygulanmasını sağlayan kişiler de merkezlerde çalışan fitness antrenörleridir. Fitness antrenörleri; spor merkezlerine üye olanlara psikolojik ve fiziksel açıdan uygun antrenman planlaması yaparak gerekli desteği sağlamaktadır. İş, aile gibi yoğunluk içerisinde yaşanan stres ve tükenme ile baş etme, zindelik kazanma, kısaca yaşam kalitesini sürdürmek açısından merkeze başvuran pek çok kişi ile yüz yüze çalışma yapmaktadırlar. İnsanlara hizmet sunan ve yüz yüze ilişki gerektiren mesleklerde tükenmenin ortaya çıkma olasılığının arttığını bildirmiştir (Babaoğlan, Altun ve Çakan, 2010). Literatürdeki bu bilgi göz önüne alındığında ve yoğun iş temposu içerisinde; stresle baş etmek, zinde kalmak, duygusal açıdan iyi hissetmek ve tükenme sendromunu önlemek açısından merkeze başvuran kişilere doğru egzersizi planlamada ve gerekli desteği sağlamada önemli rolleri olan ve pek çok kişi ile yüz yüze çalışan fitness antrenörlerinde stresle baş etme ve tükenme durumları ne düzeydedir? sorusu akla gelmiştir. Ayrıca tükenme ve stresle baş etmede nasıl bir yol izledikleri, dolayısıyla yardım arama tutumları da merak edilmiştir. Tüm bu sorulardan hareketle araştırmanın ana amacı doğrultusunda; İstanbul İli Avrupa Yakası'nda faaliyet gösteren fitness merkezlerinde çalışan antrenörlerin tükenme düzeyi, stresle başa çıkma ve yardım arama tutumları belirlenmek istenmiştir. Belirlenen tükenme düzeyi, stresle başa çıma tarzları ve yardım arama tutumlarının da; yaş, cinsiyet, günlük çalışma saati, fitness antrenörlügü dışında bir işte çalışıp çalışmama, düzenli 
spor yapma durumları ve haftalık antrenman saatleri açısından da bir farklılık gösterip göstermediği alt amaçlar olarak araştırılmak istenmiştir.

\section{Yöntem}

Araştırma evreni, İstanbul İli Avrupa Yakası'nda çalışan ve 18 yaşından büyük fitness antrenörlerinden oluşmaktadır. Evreni temsil eden örneklem ise küme örnekleme tekniği ile belirlenmiştir. Küme örnekleme tekniğinde, öncelikle bireylerin içinde yer aldıkları grupların, yani kümelerin, basit tesadüfî, sistematik ya da tabakalı örnekleme yoluyla seçilebildiği belirtilmiştir. Bu örnekleme tekniğiyle büyük bir şehri önce bölgelere, sonra mahallelere, sonra sokaklara bölerek, sonunda hanelerden oluşan örneklemler ve belirlenen hanelerden bireyler seçilebildiği açıklanmıştır. Küme örnekleme tekniğinin, evrene giren bütün bireylerin listelenemediği ancak evrenin kendiliğinden alt gruplara ayrılmış olduğu ve bu alt gruplara giren bireylerin listelenebildiği durumlarda son derece kullanışlı olduğu belirtilmiştir. (Erkuklu ve Saltık, 2001).

Araştırma evrenini belirlemek ve evrenin tamamına ulaşmak için İstanbul İli Avrupa Yakasında bulunan fitness merkezlerinin sayısı belirlenmek istenmiştir. 15.10.1999 tarihli, 23847 resmi gazete sayılı Özel Beden Eğitimi ve Spor Tesisi Yönetmeliği, İkinci Bölüm Madde 5'te belirtilen “Tesis açmak isteyen gerçek veya tüzel kişiler; açılış izni alabilmek için tesisin açılacağ1 ilin (Değişik ibare:RG-3/4/2012-28253) il müdürlüğüne dilekçe ile başvururlar." maddesinden hareketle İstanbul Gençlik Spor İl Müdürlüğü ile telefon yoluyla görüşmeler yapılmış ve görüşmeler sonrasında İstanbul ili Avrupa Yakası bölgesinde 356 adet özel fitness merkezi olduğu bilgisine ulaşılmıştır. Ancak bu merkezlerde çalışan antrenörlerin tam sayısı belirlenemediği için küme örnekleme yöntemi kullanılarak Avrupa Yakası evreni mahallelere, sonra da sokaklara bölerek, her bir mahalleden örneklem seçilerek 356 fitness merkezini temsilen küme örneklemi, basit tesadüfi örnekleme yöntemiyle seçilen fitness merkezleri ile görüşülmüş ve 56 fitness merkezinden çalıştırdıkları fitness antrenörlerine ölçeklerin uygulanması konusunda izin alınabilmiştir. Kulüpler araştırmaya izin verdikten sonra Kocaeli Üniversitesi Sağlık Bilimleri Enstitüsü Etik Kurulundan KÜ GOKAEK 2018/122 numaralı etik onay alınmıştır. Etik onay ve çalışma izinleri sonrası spor salonlarına gidilerek ve bu salonlara bağlı çalışan fitness antrenörlerine araştırma 
hakkında bilgi verilmiştir. Çalışmaya gönüllü katılmak isteyenlere ölçek uygulaması yapılmıştır. Araştırmaya gönüllü katılan ve ölçekleri yönergeye uygun dolduran toplam 401 fitness antrenörü örneklem grubunu oluşturmuştur.

\section{Veri Toplama Araçları}

Bu çalışmada fitness antrenörlerine; Tükenmişlik Ölçeği, Stresle Başa Çıkma Ölçeği, Yardım Arama Tutum Ölçeği ve literatür bilgileri ışığında araştırmacılar tarafından oluşturulan Kişisel Bilgi Formu uygulanmıştır.

Tükenmişlik Ölçeği: Pines ve Aronson (1988) tarafından geliştirilmiş ve Türkçe geçerlik ve güvenirlik çalışması Çapri (2006) tarafından yapılmıştır. Verilerin analizinde tükenmişlik puanının yüksek çıkması, katılımcıların da tükenmişliklerinin yüksek olduğu anlamına gelir. Yantlları hiçbir zaman (1), sadece bir defa (2), nadiren (3), bazen (4), sik sık (5), çoğunlukla (6), her zaman (7) şeklinde 7'li likert tipi olan bu ölçek, 21 maddeden oluşmakta ve yapılan geçerlik ve güvenirlik çalışmasında iç tutarlık katsayısı 0,93 bulunmuştur (Çapri, 2006, s.1401). Bu araştırma için güvenirlik katsayısı Cronbach alpha değeri 0,86 bulunmuştur.

Stresle Başa Çıkma Ölçeği: Folkman ve Lazarus tarafından geliştirilmiş ve tamamen uygun (1), oldukça uygun (2), kararsızım (3), biraz uygun (4), hiç uygun değil (5) şeklinde 5'li likert tipinde hazırlanmışır. Türküm tarafından 2002 yılında geçerlik güvenirlik çalışması yapılmış olan bu ölçek "Sosyal Destek Arama, Soruna Yönelme ve Sorunla Uğraşmaktan Kaçınma" alt boyutlarından oluşmaktadır. Boyutlarda puanların artması, özelliğin de arttığını göstermektedir. Ölçek bütünü için bulunan iç tutarlık katsayısı ise 0,78 ; alt ölçekler için ise sırasıyla $0.85 ; 0,80$ ve 0,65 olarak bulunmuştur (Türküm, 2002). Bu araştırma için güvenirlik katsayısı Cronbach alpha değeri ise 0,80 olarak bulunmuştur.

Yardım Arama Tutum Ölçeği: Özbay, Yazıcı, ve Şahin tarafından 1999 yılında kriter ve yapı geçerliğine uygun olarak geliştirilmiş ve kriter geçerliği için MMPI testinin K alt testi kullanılmıştır. Yapı geçerliği için ise yapılan faktör analizinde Cronbach Alpha değeri 0,79 olarak bulunmuş ve 46 maddeden oluşturulmuştur. Envanter, 1 ile 6 arasında derecelendirilmekte ve hiçbir zaman (1), çok az bir zaman (2), az bir zaman (3), bazen (4), skk sık (5), her 
zaman (6) şeklinde yanıtlanan 6'lı likert şeklinde değerlendirilmektedir (Özbay ve diğerleri, 1999, s.62). Ölçek “Kişiler Arası Açıklık, Zorlanma, Danışmaya Olan İnanç, İhtiyaç Hissetme ve Sosyal Kabul” olmak üzere beş alt boyuttan oluştuğu açıklanmaktadır. Puanların artması özelliğin de arttığ anlamına gelmektedir (Özbay ve diğerleri, 1999). Bu araştırma için güvenirlik katsayısı Cronbach alpha değeri 0,77 olarak bulunmuştur.

\section{Verilerin Analizi}

Araştırmada elde edilen veriler ortalama, standart sapma ve yüzde olarak sunulmuştur. Veriler SPSS 22.00 paket programında analiz edilmiş ve yapılan analizlerde verilerin normal dağılıma uymadıkları için nonparametrik ölçümlerden ikili küme karşılaştırmaları için Man Whitney U; ikiden fazla küme karşılaştırmaları için ise Kruskal Wallis testleri ile analiz yapılmıştır.

\section{Bulgular}

Bu bölümde katılımcların sosyo-demografik bulguları ile ölçek karşılaştırmasından elde edilen verilere yer verilmiştir. Katılımcıların sosyodemografik ve spor durumlarına ilişkin yüzdelik dağılımları analizlerin yapıldığ1 tabloda gösterilmiştir.

\section{Tükenme Ölçeğine İlişkin Bulgular}

Tablo 1. incelendiğinde cinsiyet, başka bir mesleği olup olmaması ve düzenli spor yapma durumları açısından tükenmişlik puanları istatistiksel açıdan anlamlı bir farklılık göstermemiştir ( $\mathrm{p}>0,05)$.

Tablo 1. Cinsiyet, Spor Yapma ve Başka Bir Mesleği Olup Olmama Durumlarna Göre Tükenmişlik Açısından Man Whitney U Test Sonuçları

\begin{tabular}{|c|c|c|c|c|c|c|}
\hline \multirow[b]{2}{*}{ Veriler } & \multicolumn{2}{|l|}{ Cinsiyet } & \multicolumn{2}{|c|}{ Başka bir iş/meslek } & \multicolumn{2}{|l|}{ Düzenli spor } \\
\hline & Kadın & Erkek & Var & Yok & Yapıyor & Yapmiyor \\
\hline $\mathrm{N}(\%)$ & $129(32,2)$ & $272(67,8)$ & $41(10,2)$ & $3360(89,8)$ & $360(89,8)$ & $41(10,2)$ \\
\hline Sira Ort. & 206,74 & 198,28 & 217,35 & 199,14 & 197,62 & 219,85 \\
\hline Sira top & 26669 & 53932 & 89911,5 & 71689,5 & 67190,5 & 13410,5 \\
\hline $\mathrm{Z}$ & $-0,683$ & & $-0,954$ & & $-1,379$ & \\
\hline $\mathbf{U}$ & 16804 & & 6709 & & 9220 & \\
\hline $\mathbf{P}$ & 0,49 & & 0,34 & & 0,16 & \\
\hline
\end{tabular}

Tablo 2' de yaş açısından 24 yaş ve altındaki katılımcların lehine anlamlı farklılık görülmüştür $(p<0,05)$. Ayrıca günlük çalışma saati açısından tü- 
kenmişlik puanları 13 saat ve üzerinde çalışan katılımcıların lehine anlamlı farklılık görülürken $(\mathrm{p}<0,05)$; haftalık olarak yapılan antrenman saati açısından tükenmişlik puanları istatistiksel açıdan anlamı bir farklılık göstermemiştir $(p>0,05)$.

Tablo 2. Yaş, İş ve Haftalk Spor Yapma Süresine Göre Tükenmişlik Dïzeyi Kruskal Wallis Testi Sonuçlan

\begin{tabular}{|c|c|c|c|c|c|c|c|}
\hline \multicolumn{2}{|c|}{ Değişkenler } & \multirow{2}{*}{$\begin{array}{l}\mathbf{N} \\
67\end{array}$} & \multirow{2}{*}{$\begin{array}{l}\mathbf{( \% )} \\
16,7 \\
\end{array}$} & \multirow{2}{*}{$\begin{array}{l}\text { mean } \\
179 \\
\end{array}$} & \multirow[t]{2}{*}{$\mathbf{X}^{2}$} & \multirow[t]{2}{*}{ Sd } & \multirow[t]{2}{*}{ p } \\
\hline Günlük & 3-6 saat & & & & & & \\
\hline Çalışma & $7-10$ saat & 237 & 59,1 & 194,5 & \multirow{3}{*}{9,388} & \multirow{3}{*}{4} & \multirow{3}{*}{0,05} \\
\hline \multirow[t]{2}{*}{ Saati } & 10-12 saat & 53 & 15 & 227,9 & & & \\
\hline & 13 saat ve üzeri & 44 & 11 & 233,5 & & & \\
\hline Haftalık & Antrenman yok & 55 & 13.7 & 177 & \multirow{5}{*}{3,781} & \multirow{5}{*}{4} & \multirow{5}{*}{0,43} \\
\hline Yaptığı & 1-3 saat & 42 & 10,5 & 190,33 & & & \\
\hline İdman & 4-6 saat & 152 & 37,9 & 205,10 & & & \\
\hline \multirow[t]{3}{*}{ Saati } & $7-9$ saat & 84 & 20,9 & 204,7 & & & \\
\hline & 10 saat ve üzeri & 68 & 17 & 213,4 & & & \\
\hline & 24 yaş ve altı & 117 & 29,2 & 209,21 & \multirow{5}{*}{9,528} & \multirow{5}{*}{4} & \multirow{5}{*}{0,04} \\
\hline \multirow[t]{4}{*}{ Yaş } & $25-29$ yaş & 184 & 45,9 & 203,31 & & & \\
\hline & $30-34$ yaş & 62 & 15,5 & 199,70 & & & \\
\hline & $35-39$ yaş & 21 & 5,2 & 206,5 & & & \\
\hline & 40 yaş ve üzeri & 17 & 4,2 & 117,6 & & & \\
\hline
\end{tabular}

\section{Stresle Başa Çıkma Ölçeğine İlişkin Bulgular}

Tablo 3. Katılımcıların Cinsiyet, Başka Bir Işi Olup Olmaması ve Spor Yapma Durumlarına Gore Stresle Başa Çıkma Ölçeği Alt Boyutlan Man Whitney U Test Sonuçları

\begin{tabular}{|c|c|c|c|c|c|c|c|}
\hline \multirow{2}{*}{\multicolumn{2}{|c|}{$\begin{array}{l}\text { Ölçek alt boyutları } \\
\text { ve analiz değerleri }\end{array}$}} & \multicolumn{2}{|l|}{ Cinsiyet } & \multicolumn{2}{|c|}{ Başka Bir İş/Meslek } & \multicolumn{2}{|c|}{ Spor yapma durumu } \\
\hline & & Kadın & Erkek & Var & Yok & Var & Yok \\
\hline \multirow{5}{*}{$\begin{array}{l}\text { Soruna } \\
\text { Yönelme }\end{array}$} & Sira Ort & 209,9 & 196,8 & 204,46 & 200,64 & 194,33 & 249,32 \\
\hline & Sira top & 27077 & 53524 & 8383 & 72218 & 65392,5 & 15208,5 \\
\hline & $\mathbf{Z}$ & $-1,061$ & & $-0,202$ & & $-3,543$ & \\
\hline & $\mathbf{U}$ & 16396 & & 7238 & & 7422 & \\
\hline & $\mathbf{P}$ & 0,28 & & 0,84 & & 0,001 & \\
\hline \multirow{5}{*}{$\begin{array}{l}\text { Sosyal } \\
\text { Destek }\end{array}$} & Sira Ort & 204,45 & 199,37 & 201,22 & 201 & 197,8 & 219 \\
\hline & Sira top & 26373,5 & 54227,5 & 8250 & 72351 & 67244 & 13357 \\
\hline & $\mathrm{Z}$ & $-0,122$ & & $-0,068$ & & $-1,304$ & \\
\hline & $\mathrm{U}$ & 17099 & & 7371 & & 9274 & \\
\hline & $\mathbf{P}$ & 0,68 & & 0,99 & & 0,18 & \\
\hline \multirow{5}{*}{ Kaçınma } & Sira Ort & 193,34 & 204,63 & 209,10 & 200,10 & 203,5 & 187,3 \\
\hline & Sira top & 24940,5 & 5566,5 & 8572,5 & 72028,5 & 69177 & 11424 \\
\hline & $\mathbf{Z}$ & $-0,913$ & & $-0,472$ & & $-1,006$ & \\
\hline & $\mathrm{U}$ & 16555 & & 7048 & & 9533 & \\
\hline & $\mathbf{P}$ & 0,36 & & 0,63 & & 0,31 & \\
\hline
\end{tabular}


Tablo 3'e bakıldığında; cinsiyet ve başka bir meslekle uğraşma açısından stresle başa çıkma ölçeği tüm alt boyutlarda anlamlı bir farklılık bulunmamıştır ( $p>0,05$ ). Düzenli spor yapma durumunda da; sosyal destek ve kaçınma alt boyutlarında anlamlı bir farklılık göstermez iken; soruna yönelme alt boyutunda düzenli spor yapanların lehine anlamlı farklılık göstermiştir $(\mathrm{p}<0,05)$.

Tablo 4'e bakıldığında yaş değişkeni açısından 25-29 yaş grubundakilerin lehine soruna yönelme alt boyutunda anlamlı farklllı görülmüştür $(\mathrm{p}<0,05)$. Günlük çalışma saati açısından stresle başa çıma alt boyutlarında farklılık görülmezken ( $p>0,05)$; haftalık olarak yapılan antrenman saati açısindan ise spor yapmayanların lehine anlamlı farklılık bulunmuştur $(\mathrm{p}<0,05)$.

Tablo 4. Katılımcılarnn Yaş, Spor ve Mesleki Durumlarnna Göre Stresle Başa Çıkma Bulguları (Kruskal Wallis Testi Sonuçları)

\begin{tabular}{|c|c|c|c|c|c|c|c|c|c|c|c|}
\hline \multicolumn{2}{|c|}{ Değişkenler } & & \multicolumn{3}{|c|}{ Soruna Yönelme } & \multicolumn{3}{|c|}{ Sosyal Destek } & \multicolumn{3}{|c|}{ Kaçınma } \\
\hline & $\Lambda$ & & mean & $\mathbf{X}^{2}$ & sd & mean & $\mathrm{X}^{2}$ & sd & mean & $\mathbf{X}^{2}$ & sd \\
\hline \multirow{6}{*}{ Yaş } & 24 ve alt1 & 117 & 195,8 & \multirow{5}{*}{9,81} & \multirow{5}{*}{4} & 206,14 & \multirow{5}{*}{2,53} & \multirow{5}{*}{4} & 191,2 & \multirow{5}{*}{3,18} & \multirow{5}{*}{4} \\
\hline & $25-29$ yaş & 184 & 213,17 & & & 203,84 & & & 200 & & \\
\hline & 30-34 yaş & 62 & 193 & & & 200 & & & 216,5 & & \\
\hline & $35-39$ yaş & 21 & 207,8 & & & 176,3 & & & 227,9 & & \\
\hline & 40 ve üzeri & 17 & 126 & & & 170,06 & & & 193,3 & & \\
\hline & $\mathrm{P}$ & & 0,04 & & & 0,63 & & & $0 \quad 0,52$ & & \\
\hline \multirow{5}{*}{ 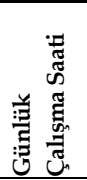 } & $3-6 \mathrm{sa}$ & 67 & 217,60 & \multirow{4}{*}{2,76} & \multirow{4}{*}{3} & 226,70 & \multirow{4}{*}{4,83} & \multirow{4}{*}{3} & 205,75 & \multirow{4}{*}{0,83} & \multirow{4}{*}{3} \\
\hline & $7-10 \mathrm{sa}$ & 237 & 198,35 & & & 192,14 & & & 200,3 & & \\
\hline & $10-12 \mathrm{sa}$ & 53 & 183,70 & & & 200 & & & 188,8 & & \\
\hline & 13 ve üzeri & 44 & 206,02 & & & 206,61 & & & 207,44 & & \\
\hline & $\mathrm{P}$ & & 0,42 & & & 0,18 & & & 0,84 & & \\
\hline \multirow{6}{*}{ 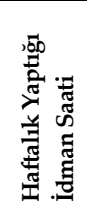 } & Yok & 55 & 260,7 & \multirow{5}{*}{19,8} & \multirow{5}{*}{4} & 260,7 & \multirow{5}{*}{3,78} & \multirow{5}{*}{4} & 230,7 & \multirow{5}{*}{6,08} & \multirow{5}{*}{4} \\
\hline & 1-3 saat & 42 & 197,9 & & & 197,9 & & & 201 & & \\
\hline & 4-6 saat & 152 & 199 & & & 199 & & & 204,20 & & \\
\hline & $7-9$ saat & 84 & 192,05 & & & 192,05 & & & 190,27 & & \\
\hline & 10 ve üzeri & 68 & 170,8 & & & 170,8 & & & 183,17 & & \\
\hline & $\mathrm{P}$ & & 0,001 & & & 0,43 & & & 0,19 & & \\
\hline
\end{tabular}

\section{Yardım Arama Tutumları Ölçeğine İlişkin Bulgular}

Tablo 5'e bakıldığında yardım arama tutumları sadece cinsiyet açısından zorlanma ve danışmaya olan inanç alt boyutlarında kadınların lehine, ihtiyaç hissetme alt boyutunda erkeklerin lehine anlamlı sonuçlar görülmüştür $(\mathrm{p}<0,05)$. Başka bir meslekle uğraşma tüm alt boyutlarda; düzenli spor yapma değişkeni açısından ise kişiler arası açıklık ile zorlanma alt boyutlarında 
anlamlı farklılık bulunmamıştır. Sadece sosyal kabul alt boyutunda düzenli spor yapmayanların lehine anlamlı sonuç elde edilmiştir $(p<0,05)$.

Tablo 5. Katılımcıların Cinsiyet, Başka Bir Işi Olup Olmaması ve Spor Yapma Durumlarına Gore Yardım Arama Ölçeği Alt Boyutları Man Whitney U Test Sonuçları

\begin{tabular}{|c|c|c|c|c|c|c|c|}
\hline \multirow{2}{*}{\multicolumn{2}{|c|}{$\begin{array}{l}\text { Ölçek alt boyutları ve } \\
\text { analiz değerleri }\end{array}$}} & \multicolumn{2}{|c|}{ Cinsiyet } & \multicolumn{2}{|c|}{ Başka Bir İş/Meslek } & \multicolumn{2}{|c|}{ Spor yapma durumu } \\
\hline & & Kadın & Erkek & Var & Yok & Var & Yok \\
\hline \multirow{5}{*}{ 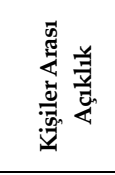 } & Sira Ort & 199,4 & 201,8 & 202,8 & 200,8 & 200,25 & 205,25 \\
\hline & Sira top & 25721,5 & 54879,5 & 8313 & 72288 & 68080,5 & 12520,5 \\
\hline & $\mathrm{Z}$ & $-0,1$ & & $-0,102$ & & $-0,311$ & \\
\hline & $\mathbf{U}$ & 173 & & 7308 & & 10110 & \\
\hline & $\mathbf{P}$ & 0,8 & & 0,91 & & 0,75 & \\
\hline \multirow{5}{*}{ 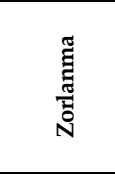 } & Sira Ort & 218,5 & 192,7 & 188,21 & 202,5 & 202,8 & 190,95 \\
\hline & Sira top & 28187,5 & 52413,5 & 7716,5 & 2884,5 & 68953,5 & 11647,5 \\
\hline & $\mathrm{Z}$ & $-2,0$ & & $-0,747$ & & $-0,0737$ & \\
\hline & $\mathbf{U}$ & 152 & & 6855 & & 9756 & \\
\hline & $\mathbf{P}$ & 0,0 & & 0,45 & & 0,46 & \\
\hline \multirow{5}{*}{ 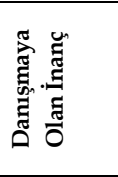 } & Sira Ort & 205,26 & 200 & 200,5 & 201,1 & 206,6 & 169,9 \\
\hline & Sira top & 26478 & 54123 & 8220,5 & 72380,5 & 70238,5 & 10362,5 \\
\hline & $\mathrm{Z}$ & $-0,50$ & & $-0,029$ & & $-2,280$ & \\
\hline & $\mathrm{U}$ & 169 & & 7359 & & 8471 & \\
\hline & $\mathbf{P}$ & 0,6 & & 0,97 & & 0,02 & \\
\hline \multirow{5}{*}{ 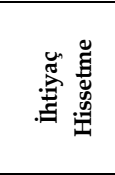 } & Sira Ort & 180,74 & 210,61 & 207,5 & 200,3 & 205,4 & 176,53 \\
\hline & Sira top & 23315,5 & 57285,5 & 8507,5 & 72093,5 & 69832,5 & 10768,5 \\
\hline & $\mathrm{Z}$ & $-2,4$ & & $-0,380$ & & $-1,794$ & \\
\hline & $\mathrm{U}$ & 14 & & 7113 & & 8832 & \\
\hline & $\mathbf{P}$ & & & 0,70 & & 0,07 & \\
\hline \multirow{5}{*}{ 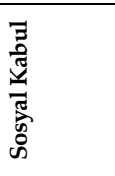 } & Sira Ort & 194,64 & 204 & 208,9 & 200,1 & 194,6 & 236,66 \\
\hline & Sira top & 25108 & 55493 & 8564 & 72037 & 66165 & 14436 \\
\hline & $\mathrm{Z}$ & $-0,0$ & & $-0,473$ & & $-2,687$ & \\
\hline & $\mathrm{U}$ & 16 & & 7057 & & 8195 & \\
\hline & $\mathbf{P}$ & 0,4 & & 0,63 & & 0,001 & \\
\hline \multirow{5}{*}{ 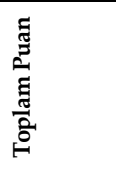 } & Sira Ort & 200,4 & 201,3 & 214,9 & 199,42 & 203,9 & 185,02 \\
\hline & Sira top & 25852,5 & 54748,5 & 8809,5 & 71791,5 & 69315 & 11286 \\
\hline & $\mathrm{Z}$ & -0, & & $-0,809$ & & $-1,170$ & \\
\hline & $\mathrm{U}$ & 17 & & 6811 & & 6395 & \\
\hline & $\mathbf{P}$ & 0, & & 0,41 & & 0,24 & \\
\hline
\end{tabular}

Tablo 6. 'da yaş açısından zorlanma ve danışmaya olan inanç alt boyutlarında 40 yaş ve üzerindeki katılımcıların lehine anlamlı farklılık görülmüştür $(p<0,05)$. Haftalık 10 saat ve üzerinde antrenman yapanların lehine danışmaya olan inanç alt boyutunda anlamlı farklılık görülmüştür $(p<0,05)$. 
Tablo 6. Katılımcıların Sosyo-Demografik Değişkenlere Göre Yardım Arama Tutum Bulguları (Kruskal Wallis Testi Sonuçlarn)

\begin{tabular}{|c|c|c|c|c|c|c|c|c|c|c|}
\hline \multirow{2}{*}{\multicolumn{2}{|c|}{ Değişkenler }} & \multicolumn{3}{|c|}{ Kişiler arası açıklık } & \multicolumn{2}{|c|}{ Zorlanma } & \multicolumn{3}{|c|}{ Danışmaya inanç } & \multirow[b]{2}{*}{ sd } \\
\hline & & mean & $\mathrm{X}^{2}$ & sd & mean & $\mathrm{X}^{2}$ & sd & Mean & $\mathbf{X}^{2}$ & \\
\hline \multirow{6}{*}{ 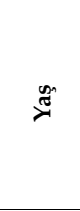 } & 24 yaş ve altı & 184,1 & \multirow{5}{*}{3.1} & \multirow{5}{*}{4} & 205,5 & \multirow{5}{*}{11,7} & \multirow{5}{*}{4} & 213,4 & \multirow{5}{*}{10,5} & \multirow{5}{*}{4} \\
\hline & 25-29 yaş & 207 & & & 195,4 & & & 191,4 & & \\
\hline & $30-34$ yaş & 202,7 & & & 187,7 & & & 181,6 & & \\
\hline & 35-39 yaş & 191,8 & & & 191,9 & & & 219,9 & & \\
\hline & 40 yaş ve üzeri & 230 & & & 290,5 & & & 267,3 & & \\
\hline & 0,53 & & & & & & 0,0 & & & \\
\hline \multirow{5}{*}{ 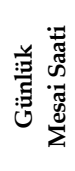 } & 3-6 saat & 172,9 & \multirow{4}{*}{5,8} & \multirow{4}{*}{3} & 193,2 & \multirow{4}{*}{3,6} & \multirow{4}{*}{3} & 198 & \multirow{4}{*}{1,54} & \multirow{4}{*}{ sina } \\
\hline & 7-10 saat & 204,3 & & & 208,9 & & & 205,9 & & \\
\hline & $10-12$ saat & 221,7 & & & 191 & & & 190,7 & & \\
\hline & 13 sa ve üzeri & 198,5 & & & 177,8 & & & 186,9 & & \\
\hline & 0,12 & & & $0, \overline{0,31}$ & & & \multicolumn{2}{|c|}{0,67} & & \\
\hline \multirow{6}{*}{ 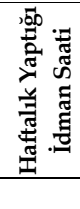 } & Ant yapmayan & 208 & \multirow{5}{*}{3,02} & \multirow{5}{*}{4} & 173,2 & \multirow{5}{*}{4,86} & \multirow{5}{*}{4} & 157,4 & \multirow{5}{*}{16,6} & \multirow{5}{*}{4} \\
\hline & $1-3$ saat & 197,5 & & & 205,3 & & & 201,2 & & \\
\hline & 4-6 saat & 192,4 & & & 204,9 & & & 213,9 & & \\
\hline & 7-9 saat & 218 & & & 196,8 & & & 181,7 & & \\
\hline & 10 ve üzeri & 195,8 & & & 173,2 & & & 231,2 & & \\
\hline & 0,5 & & & 0,3 & & & & 001 & & \\
\hline
\end{tabular}

Tablo 7. incelendiğinde sosyo-demografik özellikler açısından yaş ve günlük mesai açısından yardım arama tutumlarında herhangi bir farklılık görülmezken, haftalık olarak yapılan antrenman saati açısından sosyal kabul alt boyutunda antrenman yapmayanların lehine anlamlı farklılık görülmüştür.

Tablo 7. Katılımcılarnn Sosyo-Demografik Değişkenlere Göre Yardım Arama Tutum Bulguları (Kruskal Wallis Testi Sonuçları)

\begin{tabular}{|c|c|c|c|c|c|c|c|c|c|c|c|}
\hline \multirow{2}{*}{\multicolumn{2}{|c|}{ Değişkenler }} & \multirow{2}{*}{$\mathbf{N}$} & \multicolumn{3}{|c|}{ İhtiyaç Hissetme } & \multicolumn{3}{|c|}{ Sosyal Kabul } & \multicolumn{3}{|c|}{ Toplam Puan } \\
\hline & & & mean & $X^{2}$ & sd & mean & $\mathbf{X}^{2}$ & sd & mean & $\mathbf{X}^{2}$ & sd \\
\hline \multirow{6}{*}{$\underset{\sim}{\stackrel{\mathscr{C}}{*}}$} & 24 ve alt1 & 117 & 196,7 & \multirow{5}{*}{1,14} & \multirow{5}{*}{4} & 191,7 & \multirow{5}{*}{8,2} & \multirow{5}{*}{4} & 200,5 & \multirow{5}{*}{7,5} & \multirow{5}{*}{4} \\
\hline & $25-29$ yaş & 184 & 202,3 & & & 212,85 & & & 198,2 & & \\
\hline & $30-34$ yaş & 62 & 197,6 & & & 208,44 & & & 194,21 & & \\
\hline & 35-39 yaş & 21 & 202 & & & 155,7 & & & 138,4 & & \\
\hline & 40 ve üzeri & 17 & 227,6 & & & 165,6 & & & 274,82 & & \\
\hline & $\mathrm{P}$ & & 0,88 & & & 0,08 & & & 0,11 & & \\
\hline \multirow{5}{*}{ 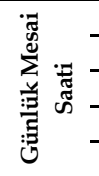 } & $3-6 \mathrm{sa}$ & 67 & 186,5 & \multirow{4}{*}{1,93} & \multirow{4}{*}{3} & 176,1 & \multirow{4}{*}{5,4} & \multirow{4}{*}{3} & 175,1 & \multirow{4}{*}{5,7} & \multirow{4}{*}{3} \\
\hline & $7-10 \mathrm{sa}$ & 237 & 205,9 & & & 209 & & & 210,53 & & \\
\hline & $10-12 \mathrm{sa}$ & 53 & 203,2 & & & 188 & & & 200 & & \\
\hline & 13 ve üzeri & 44 & 190 & & & 205 & & & 186 & & \\
\hline & $\mathrm{P}$ & & 0,58 & & & 0,14 & & & 0,12 & & \\
\hline \multirow{4}{*}{ 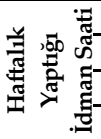 } & Ant. yok & 55 & 178 & \multirow{4}{*}{5,6} & \multirow{4}{*}{4} & 256,2 & \multirow{4}{*}{18,6} & \multirow{4}{*}{4} & 176,3 & \multirow{4}{*}{3,6} & \multirow{4}{*}{4} \\
\hline & $1-3 \mathrm{sa}$ & 42 & 217,3 & & & 199 & & & 205,1 & & \\
\hline & $4-6 \mathrm{sa}$ & 152 & 205,3 & & & 195 & & & 202,1 & & \\
\hline & $7-9 \mathrm{sa}$ & 84 & 189,2 & & & 201,4 & & & 201,8 & & \\
\hline
\end{tabular}




\begin{tabular}{lllll}
\hline 10 ve üzeri & 68 & 214,7 & 179 & 215,2 \\
\hline $\mathrm{P}$ & & 0,28 & $\mathbf{0 , 0 0 1}$ & 0,46 \\
\hline
\end{tabular}

\section{Tartışma ve Sonuç}

Araştırma için; adres bilgilerinin güncel olmaması, meslek odası olmaması gibi kurumsal bir işleyişin olmamasından kaynaklı olarak; İstanbul Avrupa Yakası Fitness antrenörleri evrenine tam ulaşılamadığı düşünülmüştür. Bu durum araştırmanın sınırlılığı olarak değerlendirilmiştir. Ancak bu sınırlılıklarla birlikte çalışmanın yürütülmesi, konuya dikkat çekerek alana katkı sunması açısından önemli kabul edilmiştir.

\section{Tükenme Ölçeğine Ait Bulgularnn Tartışılması}

Araştırma verilerinde İstanbul İli Avrupa Yakası'nda çalışan fitness antrenörlerinin cinsiyet, başka bir işle uğraşıp uğraşmama, düzenli spor yapıp yapmama ve haftalık yaptıkları idman saatine göre tükenmişlik düzeylerinin değişmediği görülmüştür. Bu değişkenler açısından tükenme duygusunda bir farklılık bulunmamasının nedeni; çalışma grubunun işleri gereği spor yapmaları olarak değerlendirilmiştir.

Başka bireylerin rekreasyon amaçlı katıldıkları bir alanın fitness antrenörlerinin işi olduğu halde, yaptıkları işlerin iletişim ve aktivite gerektiren bir iş olması ve grup halinde yapılan egzersizlerin de olumlu sonuçları olduğu, iş verimliliğinin arttırılmasında ve ikili ilişkilerin etkili hale gelmesinde pozitif etki sağladığı yönündeki literatür bilgileri de göz önüne alınd1ğında (Erkal, 1992; Ersoy, Bilgiç ve Akyol, 2008, s.9; Kanamori, Takamiya ve Inoue, 2015; Plante, Coscarelli, Caputo ve Oppezzo, 2000), çalışma grubunu oluşturan antrenörlerin de işi gereği hareketli ve genelde grup halinde yapılan aktiviteyi yönetmelerinin bu sonucu ortaya çıarmış olabileceği düşünülmektedir.

Günlük çalışma saatleri değişkeni açısından fitness antrenörlerinin tükenmişlik durumlarına bakıldığında; 13 saat ve üzeri saatlerde çalışan antrenörlerin tükenmişlik düzeylerinin arttğ̆ görülmüştür. Literatürde; işi yapan kişilerde; artan iş yükü ve iş saatleri ile başa çıkacak bir kontrol mekanizmasına sahip olunmadığında, bilgi birikimi, yetenek ve yeterlilikler, kaynaklar gibi durumlar açısından kendilerini eksik olarak değerlendirecekleri için zamanla kaygı ve stres sorunlarının ortaya çıtığı ve tükenmişlik 
yaşandığı belirtilmiştir (Köse, 2019, s.12; Roberts, 2020; Schaubroeck ve Merritt, 1997; Temel, 2006). Mesai saatinin fazla olmasının, tükenmişliği etkileyen sebeplerden olduğu, antrenörlerin kendine zaman ayıramamasının, saatlerin fazla olmasıyla hissedilen yorgunlukların, aynı ortamda fazla saat geçirilmesiyle birlikte bir tür psikolojik baskı gibi algılanarak tükenmişliği ortaya çıkarttığı düşünülmüştür.

Mesleki faaliyetlerini sürdüren fitness antrenörlerinin yaş değişkenine göre tükenmişlik düzeyleri incelendiğinde; 24 yaş ve altındaki gruplarda bulunan antrenörlerin tükenmişlik düzeylerinin arttığ 1 görülmüştür. Tükenmişliğe ilişkin yapılan araştırmalarda da, bu çalışmayı destekler şekilde daha genç olan çalışanların tükenmişlik seviyesinde artış olduğu belirtilmiştir (Saatoğlu ve Karagün, 2014). Bu sonuçlarda; genç yaş gruplarında tükenmenin daha yüksek çıkmasının antrenörlerin deneyimsizlikleriyle ilişkili olduğu, genç antrenörlerin çalıştıkları sektörü yeterince tanımamaları, iş talebi beklentileri ve kişisel kapasite arasında denge olması durumunda tükenme geliştiği (Kalimo, Pahkin, Mutanen ve Toppinen-Tanner, 2003; Kanai-Pak, Aiken, Sloane ve Poghosyan 2008; Saatoğlu ve Karagün, 2014), yeni başlayan antrenörlerde ekonomik açıdan aylık ücretlerinin daha düşük olmasından kaynaklı olabileceği düşüncesini doğurmuştur. Ayrıca işe alıştırma eğitimlerinin çalışanların işe uyumu, işini sevmesi ve aidiyet duygusu kazandırılması açısından önemli olduğunu ileri süren araştırmalarla (Topaloğlu ve Sökmen, 2003) değerlendirildiğinde; fitness antrenörlüğüne yeni başlayan genç antrenörlere yönelik eğitimlerin tasarlanması, özellikle uyum eğitimlerinin işini sevmeye, aidiyet duygusu geliştirmeye yönelik ve dolay1sıyla da tükenme ile baş etmede destekleyici olarak planlanarak, sonuçlarının da test edilmesinin konuya daha açıklık kazandıracağı düşünülmüştür.

\section{Stresle Başetme Ölçeğine Ait Bulgularnn Tartışılması}

Katılımcların; cinsiyet, başka bir işle uğraşıp uğraşmama ve günlük çalışma süresi açısından stresle başetme ölçeği alt boyutlarının hiç birinde anlamlı bir farklılık bulunmamıştır. Fitness antrenörlerinin spor yapıp yapmama durumuna göre stresle başetme alt boyutları incelendiğinde; sadece spor yapanlar lehine soruna yönelme alt boyutunda anlamlı farklılık bulunmuştur. Literatüra bakıldığında spor yapmanın duygusal açıdan; özgüveni yükselttiği, negatif düşünceleri uzaklaştırdığı, strese uyum sağlayıcı dolayısıyla 
da stresi azaltıcı etkileri olduğu (Demir ve İlhan, 2019; Fox, 1999; İlhan, 2010; Karakaya, Coşkun ve Ağaoğlu, 2006, s.163; Mumcu ve Mumcu, 2019; Steptoe ve Butler, 1996) bilgilerinin bulunan sonuçları desteklediği düşünülmüştür.

Sporun stresle başetmede etkili olduğunu, özellikle soruna yönelme alt boyutunda etkili olduğunu gösteren bir diğer bulgu da, antrenörlerinin haftalık antrenman saatlerine göre stresle başa çıkma ölçeği soruna yönelme alt boyutunda pozitif yönde bir etki yaratması, antrenman saati arttıkça stresle baş etme puanlarının da anlamlı bir şekilde yükselmesidir. Ayrıca literatürde de; sporun rahatlamayı sağlayan serotonin, endorfin gibi hormonları salgılatarak; duygusal açıdan bireylerde iyi hissetme duygusu yarattığı, stresle başetmede destekleyici olduğu bildirilmiştir (Baltaş ve Baltaş, 2008, s.194, 202; Bond, Lyle, Tappe, Seehafer ve D'Zurilla, 2002, s.329-343; Ersoy, ve diğerleri, 2008, s.12; Penedo ve Dahn, 2005; p.189-192; Tarhan, 2005). Yine stresin tükenmeyi tetikleyici bir etken olduğu, stresörler ile tükenme duygusu arasında pozitif ilişkilerin bulunduğu yapılan araştırmalar sonucunda ortaya konmuştur (Moran, 2004; Sucuoğlu ve Kuloğlu, 1996).

Yaş değişkenine göre, 25-29 yaş aralığında bulunan antrenörlerin, soruna yönelme alt boyutunda aldıkları puanlarda anlamlı farklılı̆̆a rastlanmıştır. Literatür incelendiğinde; bu çalışma bulgularını destekler şekilde 20-29 yaş aralığındaki bireylerin stres ortalamalarının yüksek olduğu belirlenmiştir (Yıldırım, 2008, s.160). Bu sonuçlarla bakıldığında örneklem grubunu oluşturan 25-29 yaş grubundaki fitness antrenörlerinin tecrübe kazanma dönemini geçtikleri, kendilerini stajyer hoca seviyesinin üzerine çıkarak sorumluluk aldıkları ve bu sorumlulukla birlikte gelen stresli durumu ve problemi çözme girişiminde bulunmalarının bir etkisi olmuş olabileceği düşünülmüştür.

\section{Yardım Arama Ölçeğine Ait Bulguların Tartışılması}

Antrenörlerin verdiği cevaplar analiz edildiğinde; cinsiyet değişkenine göre yardım arama tutumları ölçeğinin alt boyutu olan zorlanma ve ihtiyaç hissetme açısından erkeklerin daha fazla zorlandığı, ancak danışmaya daha çok ihtiyaç hissettikleri sonucuna ulaşılmıştır. Yapılan araştırmalarda kadınların; paylaşıma daha açık olmaları, düşüncelerini yalın ve açık anlatabilmelerine bağlı olarak, duygusal problemlerini daha çabuk kabullendiği ve pro- 
fesyonel yardıma ihtiyaç duydukların fark edip ifade ettikleri (Ang, Lim, Tan ve Yau, 2004: Gündüz, 2019; Johnson, 1988); erkeklerin kendini açma durumlarının daha uzun bir süreçte gerçekleştiği, bu konuda zorluk çektikleri ve sorunun varlığını kabullenmelerinde zorlandıkları açıklanmıştır (Goleman, 1998, çev, 2018; Levant, 1990; Özbay, Terzi, Erkan ve Çankaya, 2011). Bu bilgilerle analiz sonuçları yorumlandığında; erkeklerin yardım aramada kadınlara göre daha fazla ihtiyaç hissettikleri beklenen bir sonuç olarak karşımıza çıkmaktadır.

Düzenli olarak spor yapan antrenörlerin yardım arama tutumlarından danışmaya olan inanç alt boyutundaki puanlarının, spor yapmayan antrenörlere göre daha yüksek olduğu sonucuna ulaşılmıştır. Yapılan çalışmalar incelendiğinde branş farketmeksizin düzenli spor yapanların kaygı bozukluğu ve stres seviyelerinin spor yapmayanlara göre daha düşük olduğu (Canan ve Ataoğlu, 2010) bilgileri göz önüne alındığında; spor yapan antrenörler psikolojik ve fizyolojik açıdan iyi hissedecekleri için profesyonel desteğe bakış açları spor yapmayanlara göre daha olumlu olabileceği düşünülmüştür.

Yardım arama tutumları, yaş gruplarına göre incelendiğinde; kırk yaş ve üzerinde olan fitness antrenörlerinin danışmaya olan inançları genç olan antrenörlere göre daha yüksek olduğu ancak zorlandıkları sonucuna ulaşılmıştır. Danışmaya olan inanç, uzman bir yardım arayan kişilerin güvenini ve bağlılığını barındırdığı, böylelikle bu kişilerin psikolojik sorunlarının farkında olduğu ve bunu kabul ettiği; bu boyutun yardımın işe yararlılığını sorgulayan bir yapıda olduğu ileri sürülmüştür(Özbay ve diğerleri, 1999). $\mathrm{Bu}$ bilgilerle bakıldığında; kırk yaş ve üzerinde olan fitness antrenörlerin emekli olmaya yakın bir yaş grubunda olmaları, tecrübelerinin fazla olması sonucunda kendini tanımaları, psikolojik olarak problemlerini fark etmeleri ve sorunlarına profesyonel destek almada pozitif bir bakış açısı geliştirmiş olabilecekleri düşünülmüştür.

Antrenörlerin yapmış oldukları antrenman saatlerine gore, haftalık ortalama 10 saat ve üzerinde antrenman yapanların danışmaya olan inançlarının daha fazla olduğu görülmüştür. İnsanın özel yetenekleri olan ve yaşamını merkezi sistemle kontrol altında tutan bir mekanizması olduğu; egzersiz durumlarında solunum, sindirim, boşaltım ve iskelet-kas sisteminin istenilen düzeyde verimli tutulmasını sağladığı, uzun süre hareket etmeyen bireylerin de sağlık sıkıntıları ile savaşmak durumunda kaldığı (Can, Arslan 
ve Ersöz, 2014, s.4; Çiçek, 2010) bilgileriyle değerlendirildiğinde antrenman yapan antrenörlerin iyi hissettikleri, olaylara bakış açılarının olumlu olması sonucunda sağlık konularında farkındalıklarının arttığı, böylece profesyonel yardıma yönelik tutumları ve danışmaya olan inançlarının da artmış olabileceği düşünülmüştür.

Antrenörlerin haftalık olarak yapmış oldukları antrenman saatlerine göre yardım arama tutumları ele alındığında; spor yapmayan antrenörlerin sosyal kabul alt boyutunda farklılık olduğu sonucuna ulaşılmıştır. Fiziksel aktivite ve sporun, bireylerin zihinsel, bilişsel ve sosyal gelişimlerine destek verdiği, kişilerin yaşadıkları toplumlarda daha zinde, sağlıklı, kaliteli, mutlu ve huzurlu olmalarında önemli bir etkiye sahip olduğu belirtilmiştir (Mumcu ve Mumcu, 2019; Özdenk, 2018). Ayrıca spor yapanların spor yapmayanlara göre sağlıklı bir ruha ve bedene sahip olacağı açıklamasıyla (Can, ve diğerleri, 2014, s.4; Özdenk, 2018) bakıldığında; spor yapanların spor yapmayanlara göre psikolojik açıdan daha iyi hissedecekleri, stresle başetme gibi konularda daha fazla becerileri olacağı düşünülebilir.

Sonuç olarak, antrenörlerin yaş artışına paralel olarak tükenmişlik duygusunun da anlamlı şekilde yükseldiği göz önüne alındığında; motivasyon arttırıcı çalışmalarla birlikte kurum içinde psikolojik açıdan rutin kontrollerin yapılması, tükenme gibi sorunların önlenmesi açısından, kurum içi aktiviteler ve farklı organizasyonlar planlanması, serbest zaman etkinliklerine katılımları açısından aktivite planının yanısıra mesai saatlerinin de düzenlenmesi önemli görülmüştür. Ayrıca fitness antrenörlerinin bağlı olduğu meslek odası, federasyon vb. kurumların daha sistemli ve kurumsal çalışması, antrenörlerin bilgilerinin güncel tutulması ve konu ile ilgili istatistiklerin ulaşılabilir olması mesleki kurumsallık ve bazı organizasyon planlanmasinda önemli olduğu düşünülmüştür. 


\title{
EXTENDED ABSTRACT
}

\section{Burnout, Stress Coping and Help-seeking Attitudes of Istanbul European Side Fitness Coaches}

\author{
Şeval Kayğusuz - Elif Karagün \\ İstanbul Gedik University-Kocaeli University
}

It is suggested to participate in exercise programs to overcome stress, to prevent burnout syndrome and to feel emotionally good. People living in cities usually go to fitness centres to do sports. Fitness trainers organize the exercise plan that is needed in the fitness centres. When it is considered that the burnout in some professions that require intensive interpersonal relations has increased, fitness trainers that work with many people face to face organize them exercise programs to deal with daily stress. Therefore, it is wondered what level is their burnout level; how they cope with stress; and their attitudes towards seeking for help for this kind of problems.

Thus, it is aimed to determine the burnout level, the attitudes towards seeking for help and stress level of fitness trainers working at sport centres in the European Part of the Province of Istanbul. It is also aimed to find out if there is a difference between their burnout levels, the way they deal with stress, the attitudes towards seeking for help and their ages, gender, daily working hours, if they work at other jobs apart from fitness training, if they regularly do sports, their workout hours. With this aim, the universe of this study was formed with 356 fitness centres that are in the European Part of the Province of Istanbul and the sample of the study was formed with 401 volunteering fitness trainers working at 56 sport centres after they were informed about our study.

Fitness Trainers were applied Burnout Scale, Stress Coping Scale, Seeking Help Attitude Scale and Personal Information Form.

The data collected in this study was presented as average, deviation, and percentage. Man Whitney $U$, one of the nonparametric measurements for binary clusters, was applied because the data do not fit with a normal distribution; Kruskal Wallis tests were used for the comparisons of more than binary clusters. 
When the findings were examined; it was observed that the burnout level did not change according to the gender. The reason for this was evaluated with the fact that the work-group does sports. No significant difference was found between the burnout level and their doing another job; doing regular sport; and their training hours.

Ersoy et al stated $(2008$, p.9) that doing exercise plays an important role in protecting and preventing the person from chronic diseases, preventing and promoting the social health; doing exercise and sport has a positive effect on increasing the efficiency at work, and strengthening bilateral relations. When this comment was evaluated, it was thought that there is no significant difference between the professions of the research group and their burnout level. It was observed that burnout level of trainers who have more than 13 working-hours increased significantly. In addition, the burnout level was found to be high for the trainers who are in the age group under 24.

When the findings about coping with stress were evaluated, it was observed that there was a positive emotional effect on the training hour and the sub-dimension of the Stress Coping Scale. That means as the training hour increased, the scores of coping with stress increased significantly, as well. As for the age variable, a significant difference was found in the subdimension of Dealing with the Problem of the trainers who are between the ages of 25-29. It was also traced that Dealing with the Problem increased for the trainers aged over 40. It was understood that in terms of gender; men have more difficulty in the sub-dimension 'Strain' of 'Seeking Help Attitude Scale';

The findings of this study show us that men need to seek help more than women, which is an expected result.

Another finding of this study is that in the 'Seeking Help Attitude Scale', the scores in 'Faith for Consulting' sub-dimension of trainers who regularly do sports were higher than those who do not. It was concluded that in the sub-dimension of 'Faith for Consulting' in 'Seeking Help Attitude Scale'; the scores of fitness trainers aged over 40 were found to be higher than younger trainers, however, they have difficulties.

It was seen that trainers who do more than 10 hours of training a week need more faith for consulting. 
When we examined Seeking Help Attitudes of the trainers according to their weekly-trainings, we concluded that there is a difference in social acceptance of trainers who do not do sports.

As a result, considering the high burnout of young trainers in parallel with the increase in their ages, it was considered as important to increase the number and variety of in-house activities, revising their working-hours as the trainers also need leisure time. In addition, some foundations such as chamber of profession or federations to which fitness trainers are affiliated should work more systematically and institutionally. Trainers should be updated, as well. All of these are thought to be important for the trainers about their professional attitudes and their feelings of burnout.

\section{Kaynakça}

Alpaslan, A. H. (2012). Ergen ruh sağlı̆̆ ve spor. Kocatepe Tip Dergisi, 13(3), 181-185.

Ang, R. P., Lim, K. M., Tan, A. G. ve Yau, T. Y. (2004). Effects of gender and sex role orientation on help-seeking attitudes. Current Psychology, 23(3), 203-214. doi: 10.1007/s12144-004-1020-3

Aylaz, R., Güllü, E., ve Güneş, G. (2011). Aerobik yürüme egzersizin depresif belirtilere etkisi. DEUHYO ED, 4(4), 172-177.

Babaoğlan, E., Akbaba Altun, S. ve Çakan, M. (2010). İlköğretim okulu yöneticilerinin tükenmişlik düzeyi. Türk Ĕgitim Bilimleri Dergisi, 8(2), 355-373.

Baltaş, A. ve Baltaş, Z. (2008). Stres ve başaçıma yolları. İstanbul: Remzi Kitabevi.

Bezliudnyi, O., Kravchenko, O., Maksymchuk, B., Mishchenko, M., ve Maksymchuk, I. (2019). Psycho-correction of burnout syndrome in sports educators. Journal of Physical Education and Sport, 19(3), 1585-1590.

Bond, D. S., Lyle, R. M., Tappe, M. K., Seehafer, R. S., ve D'Zurilla, T. J. (2002). Moderate aerobic exercise, Tai Chi, and social problem-solving ability in relation to psychological stress. International Journal of Stress Management, 9(4), 329-343.

Brown, C. (2003). Low morale and burnout: is the solution to teach a values-based spiritual approach? Complementary Therapies in Nursing Et Midwifery, 9(2), 5761. doi: $10.1016 / S 1353-6117(03) 00012-X$

Byrne A. ve Byrne D. G. (1993). The effect of exercise on depression, anxiety and ot mood states-a review. Journal of Psychosomatic Research, 37(6), 565-574. Doi: 10.1016/0022-3999(93)90050-p

Can, S., Arslan, E. ve Ersöz, G. (2014). Güncel bakış açısı ile fiziksel aktivite. Spormetre Beden Eğitimi ve Spor Bilimleri Dergisi, 12(1), 1-10. doi: 10.1501/Sporm_0000000248 
Canan, F. ve Ataoğlu, A. (2010). Anksiyete, depresyon ve problem çözme becerisi algisı üzerine düzenli sporun etkisi. Anatolian Journal of Psychiatry, 11(38), 3843.

Çapri, B. (2006). Tükenmişlik ölçeği-kısa formu ile eş tükenmişlik ölçeği-kısa formúnun Türkçe uyarlaması ve psikoanalitik-varoluşçu bakış açısından mesleki ve eş tükenmişlik ilişkisi. Kuram ve Uygulamada Eğitim Bilimleri, 13(3), 1393-1418.

Çiçek, İ. E. (2010). İnterferon tedavisi sonucu gelişen depresyon ile oksidatif stres ve nörotrofik faktörlerin ilişkisi. Yayımlanmamış doktora tezi, Selçuk Üniversitesi, Konya.

Demir, G. T., ve İlhan, E. L. (2019). Spora kathlim motivasyonu: görme engelli sporcular üzerine bir araştırma. Gaziantep Üniversitesi Spor Bilimleri Dergisi, 4(1), 157-170.

Dolaşır, S. (2006). Antrenörlük etiği ve ilkeleri. Ankara: Gazi Kitabevi.

Ekeland, E., Heian F., Hagen, K.B., Abbott, J. ve Nordheim, L. (2004). Exercise to improve self-esteem in children and young people. Cochrane Database of Systematic Reviews, 1.

Enzmann, D., Schaufeli, W. B, Janssen, H. ve Rozeman, A. (1998). Dimensionality and validity of the burnout measure. Journal of Occupational and Organizational Psychology, 71(4), 331-351.

Erkal, M. (1992). Sosyolojik açıdan spor. Ankara: Türk Dünyası Araştırmaları Vakfı Yayınları.

Erkuklu, G. ve Saltık, A. (2001). Bilimsel araştırmalarda örneklem seçimi. Balkan Medical Journal, 18(3), 241-248.

Ersoy, G., Bilgiç, P. ve Akyol, A. (2008). Fiziksel aktivite, beslenme ve sağhlkl yaşam. Ankara: Klasmat Matbaacilik.

Fox K. R. (1999). The influence of physical activity on mental wellbeing. Public Health Nutrition, 2(3a), 411- 418. doi: 10.1017/S1368980099000567

Goleman, D. (2018). Duygusal zeka. Çev. B. Yüksel, İstanbul: Varlık Yayınevi.

Gündüz, S. (2019). Beden eğitimi ve spor öğretmenliği ve sinfföğretmenliği bölümü öğrencilerinin algilanan stres düzeyleri ile stresle başa çkma tarzlarmm incelenmesi. Yayımlanmamış yüksek lisans tezi, Afyon Kocatepe Üniversitesi, Afyon.

İlbars, Z. (1994). Kültür ve stres. Kriz Dergisi. 2(1), 177-179. https://doi.org/10.1501/Kriz 0000000058

İthan, E. L. (2010). Hareketsiz yaşamlar kültürü ve beraberinde getirdikleri. Milli Prodüktivite Merkezi Verimlilik Dergisi, 3, 195-210.

Johnson, M. E. (1988). Influences of gender and sex role orientation on help-seeking attitudes. The Journal of Psychology, 122, 237-241. 
Kalimo R., Pahkin K, Mutanen P. ve Toppinen-Tanner S. (2003). Staying well or burningout at work, work characteristics and personal resources aslongtermpredictors. Work and Stress, 17(2), 109-122.

Kanai-Pak, M., Aiken, H. L., Sloane, M. D. ve Poghosyan, (2008). Poor work environments and nurse inexperience are associated with burnout, job dissatisfaction and quality deficits in Japanese hospitals. Journal of Clinical Nursing, 17(24), 3324-3329.

Kanamori, S., Takamiya, T., ve Inoue, S. (2015). Group exercise for adults and elderly: Determinants of participation in group exercise and its associations with health outcome. The Journal of Physical Fitness and Sports Medicine, 4(4), 315320.

Karakaya, I., Coşkun, A. ve Ağaoğlu, B. (2006). Yüzücülerin depresyon, benlik saygısı ve kayg1 düzeylerinin değerlendirilmesi. Anatolian Journal of Psychiatry, 7, 162166.

Köse, Ö. (2019). Presenteeism (İşte var olamama) ile örgütsel özdeşleşme ve tükenmişlik arasındaki ilişkinin analizi. Yayımlanmamış yüksek lisans tezi, İstanbul Sabahattin Zaim Üniversitesi, İstanbul.

Kut, S. (1994). Toplumsal değişim, kurumların yeniden yapılanması ve ruh sağlığı. Kriz Dergisi, 2(1), 180-184.

Levant, R. F. (1990). Psychological services designed for men: a pyschoeducational approach. Psychotherapy, 27(3), 309-31.

Lyle, J. (2002). Sports coaching concepts: a framework for caoches' behaviour. London: Routledge.

Maslach, C., Schaufeli, W.B. ve Leiter, M.P. (2001). Job burnout. Annual Reviews Psychology, 52, 397-422.

Moran A. (2004). Sport and exercise psychology: A critical introduction. Routledge. New York.

Mumcu, N. ve Mumcu, H. E. (2019). Sporun stres ve mutluluk üzerine etkileri. Ankara: Akademisyen Kitabevi A.Ş.

Özbay, Y., Yazıcı, H. ve Şahin, B. (1999). Yardım arama tutum ölçeği: geçerlik ve güvenirlik çalışması. 10. Ulusal Psikolojik Danışma ve Rehberlik Kongresi.

Özbay, Y., Terzi, Ş., Erkan, S., ve Çankaya, Z. C. (2011). Üniversite öğrencilerinin profesyonel yardım arama tutumlarl, cinsiyet rolleri ve kendini saklama düzeyleri. Pegem Ĕ̆itim ve Öğretim Dergisi, 1(4), 59-71.

Özdenk, S. (2018). Beden eğitimi ve spor, faydaları, önemi ve sınıflandırılması. Spor Bilimlerinde Akademik Araştırmalar, 77-89. 
Penedoa J. F. ve Dahna, J. R. (2005). Exercise and well-being: a review of mental and physical health benefits associated with physical activity. Current Opinion in Psychiatry, 18(2), 189-193. 15.06.2020 tarihinde file:///C:/Users/vaio/Downloads/Exercise and well being a review of me ntal and.13.pdf/ adresinden erişildi.

Plante, T. G., Coscarelli, L., Caputo, D., ve Oppezzo, M. (2000). Perceived fitness predicts daily coping better than physical activity or aerobic fitness. International Journal of Stress Management, 7(3), 181-192.

Roberts, W. O. (2020). Wellness and life balance for sports medicine physicians: recognizing physician burnout. Current Sports Medicine Reports, 19(2), 50-52.

Saatoğlu, A. M. ve Karagün, E. (2014). Assessment of bunout levels of sport clup administrators. Nigde University Journal Of Physical Education and Sport Sciensces, $8(1), 49-59$.

Salmon, P. (2001). Effects of physical exercise on anxiety, depression, and sensitivity to stres: a unifying theory. Clinical Psychology Review, 21, 33-61.

Samur, Ü. G. ve Samur, S. (2017). Sporda stres yönetimi ve teknikleri. Ankara: Gazi Kitabevi.

Schaubroeck, J. ve Merritt, D. E. (1997). Divergent effects of job control on coping with work stressors: The key role of self-efficacy. Academy of Management Journal, $40(3), 738-754$.

Steptoe A. ve Butler N. (1996). Sports participation and emotional wellbeing in adolescents. The Lancet, 347, 1789-1792.

Sucuoğlu, B. ve Kuloğlu, N. (1996). Özürlü çocuklarla çalışan öğretmenlerde tükenmişliğin değerlendirilmesi. Türk Psikoloji Dergisi, 10(36), 44-60.

Tarhan, N. (2005). Mutluluk psikolojisi. İstanbul: Timaş Yayınları.

Temel, A. (2006,). Organizasyonlarda işkolizm ve işkolik çalışanlar. "İş, Gǚs" Endüstri İlişkileri ve Insan Kaynaklarn Dergisi, 8(2), 104-127.

Topaloğlu, M., ve Sökmen, A. (2003). İşe alıştırma (oryantasyon) eğitiminin etkinliği ve işgören performansı ilişkisi: Ankara'da Bir Uygulama Gazi Üniversitesi Ticaret ve Turizm Ĕ̈̆itim Fakültesi Dergisi, 2, 126-151.

Torelli, J. A. ve Gmelch, W. H. (1992). Occupational stress and burnout in educational administration. Paper Presented at the Annual Meeting of the American Educational Research Association, San Francisco.

Türküm, S. (2000). Üniversite öğrencilerinin psikolojik yardım almaya ilişkin tutumları ve kendini açma eğilimleri. Anadolu Üniversitesi Eğitim Fakültesi Dergisi, 10(2), 205-220. 
Yıldırım, S. (2008). Muhasebe öğretim elemanları ve meslek mensuplarının mesleki stress düzeyi üzerine bir araştırma. Muhasebe ve Finansman Dergisi, (38), 153162.

\section{Kaynakça Bilgisi / Citation Information}

Kayğusuz, Ş. ve Karagün, E. (2020). İstanbul Avrupa Yakası fitness antrenörlerinin tükenmişlik, stresle başa çıkma ve yardım arama tutumları. OPUS-Uluslararası Toplum Araştırmaları Dergisi, 17(35), 2102-2124. DOI: 10.26466/opus.784499 